\title{
O CORPO A PARTIR DO MOVIMENTO NUDISTA: RIO DE JANEIRO NA DÉCADA DE 1950
}

\author{
HE BODY SEEN FROM THE NUDIST MOVEMENT: RIO DE JANEIRO IN THE \\ 1950s
}
EL CUERPO A PARTIR DEL MOVIMIENTO NUDISTA: RIO DE JANEIRO EN LA DÉCADA DE 1950

\author{
Carlos Herold Junior*, Alisson Bertão Machado**, \\ Carolini Aparecida Campanholi**, Bruna Solera*, Pedro Gabriel Gil Parizotto*
}

Palavras chave:

História.

Corpo humano. Nudismo.

Brasil.

\section{Keywords:}

History.

Human body.

Nudism.

Brazil.

Palabras clave: Historia.

Cuerpo humano. Nudismo.

Brasil.

\begin{abstract}
Resumo: 0 objetivo deste trabalho é estudar representações sobre o corpo, produzidas a partir do movimento nudista. Isso será feito abordando as disputas sobre as fotografias publicadas em revistas nudistas durante a década de 1950 no Rio de Janeiro. Ao lado das próprias revistas, jornais, documentos judiciais e livros serão utilizados como fontes primárias, abordadas por meio do conceito de representação (CHARTIER, 2002). Observou-se que as publicações nudistas e a expansão das práticas do movimento produziram representações que evidenciam tensões sobre a relevância do corpo e da exposição corporal na sociedade carioca do período em questão.
\end{abstract}

Abstract: This work studies representations of the body produced within the nudist movement by looking into debates over photographs published in nudist magazines during the 1950s in Rio de Janeiro. Besides magazines themselves, newspapers, legal documents and books will be used as primary sources addressed through the concept of representation (CHARTIER, 2002). It was found that nudist publications and the expansion of the movement's practices produced representations that show tension regarding the importance of bodies and body exposure in Rio de Janeiro's society of that time.

Resumen: El objetivo de este trabajo es estudiar representaciones sobre el cuerpo, producidas a partir del movimiento nudista. Esto se hará abordando las disputas sobre las fotografías publicadas en revistas nudistas durante la década de 1950 en Rio de Janeiro. Además de las revistas, serán utilizados periódicos, documentos legales y libros como fuentes primarias, abordadas a través del concepto de representación (Chartier, 2002). Se observó que las publicaciones nudistas y la expansión de las prácticas del movimiento produjeron representaciones que muestran tensiones sobre la relevancia del cuerpo y de la exposición corporal en la sociedad de Rio de Janeiro de la época.
*Universidade Estadual de Maringá. Maringá, PR, Brasil. E-mail: carlosherold@hotmail.com; brunasoleraef@gmail.com; pedrogilp@ hotmail.com

**Instituto Federal de Educação Tecnológica. Curitiba, PR, Brasil. E-mail: carocampanholi@uol.com.br; alisson.machado@ifpr.edu.br

Recebido em: 31-05-2016 Aprovado em: 09-10-2016

DOI: http://dx.doi.org/10.22456/1982-8918.65075 (c) (1) () Licence 


\section{INTRODUÇÃO}

Estudaremos a história do movimento nudista, considerando-o um componente das pedagogias do corpo gestadas nas primeiras décadas do século XX. Soares (2016) afirma que podemos "[...] aludir a pedagogias, ou seja, formas mais concretas de intervenção no corpo individual e social percebidas como salvaguarda, prevenção e, ao mesmo tempo, possibilidade de fabricação de novas sensibilidades" (SOARES, 2016, p.14). Ao assumirmos 0 nudismo como"[...] um conjunto de doutrinas que propõem um modo particular de perceber a natureza e incluem práticas nas quais se coloca a questão do corpo" (VILLARET, 2012, p. 707), avaliaremos sua importância na "fabricação" acima mencionada.

Reagindo à expansão da alopatia junto com o vegetarianismo, a hidroterapia, a helioterapia e a cultura física, o nudismo propunha como ideia fundamental "[...] o contato com a natureza e seus elementos"(VILLARET, 2005, p.12) (tradução nossa). Na primeira metade do século XX, houve uma mobilização em torno de um "projeto de regeneração do corpo" apoiado na defesa de uma volta a um "estado natural" (BAUBÉROT, 2004, p.15) (tradução nossa). Foram práticas nas quais se colocou "[...] a questão do corpo em suas relações com 0 pudor, a nudez, a alimentação, o exercício, mas também com o lazer, a sexualidade, o turismo etc." (VILLARET, 2012, p.707). Essa ênfase do naturismo e, sobretudo, do nudismo, ao corpo, pautou-se na defesa de uma "educação integral" (VILLARET, 2016, p.71), ponto pacífico entre numerosas vertentes naturistas que, em outros assuntos - por exemplo, sobre a nudez - não tinham concordância'.

A ênfase ao corpo no naturismo em geral e no nudismo em particular se apoiou em "[...] angústias de uma sociedade hipocondríaca, convencida da degenerescência dos corpos e da delinquência dos costumes" (VILLARET, 2016, p.86). Esse diagnóstico feito a partir da Europa aplica-se ao Brasil. As "linguagens da decadência" (HERMAN, 1999), ao lado da expansão de outras manifestações culturais relacionadas ao corpo, como o esporte (LINHALES, 2009), estimularam as defesas e, consequentemente, as críticas ao movimento nudista no contexto brasileiro. Nosso objetivo é estudar as representações(CHARTIER, 2002) sobre o corpo no tensionamento entre aceitação e recusa ao nudismo no Rio de Janeiro, durante a década de 1950. Nos anos 1950 a circulação de revistas nudistas na cidade do Rio de Janeiro gerou críticas ao que nelas era, sobretudo, visto. Elas encetaram discussões, reprovações, apreensões policiais e disputas judiciais.

Ao lado das revistas a imprensa periódica forma a base documental do estudo. Ao tomarmos as dissensões sobre o que era publicado nas revistas, lembramos que Del Priore (2011) diagnostica nas primeiras décadas do século XX um movimento crescente de imagens com conotações sexuais: o "sucesso dos nus em revistas foi total" (DEL PRIORE, 2011, p.131). Ao citar as revistas aqui estudadas, ela conclui que "As fotos naturistas iam à contramão do que se fazia na pornografia: eram totalmente despossuídas de erotismo" (DEL PRIORE, 2011, p. 131). Problematizaremos essa assertiva, sublinhando as disputas entre representações que buscavam estipular o lugar público da nudez. Se considerarmos que a nudez gera "atividades, pensamentos e sentimentos contraditórios" (CARR-GOMM, 2010, posição 72) (tradução nossa), a clareza que Del Priore (2011) vê existir no que era exibido nas revistas não era compartilhada por críticos, leitores e, nem mesmo, editores daquelas publicações nos anos em questão.

1 Embora os termos naturismo e nudismo frequentemente apareçam como sinônimos, é importante especificar que na expansão do naturismo no início do século XX numerosas práticas foram defendidas e, muitas vezes, elas se opunham. Para citarmos um exemplo, Paul Carton (18751947), um dos precursores do vegetarianismo, era contra o nudismo. 
Metodologicamente, com Chartier (2002) abordamos as representações que se coloca ramentre diferentes grupos sociais que dividiam o mesmo contexto com olhares discrepantes em relação ao corpo. A análise das fontes deter-se-á nos posicionamentos em que as fotografias das revistas eram o centro da atenção de articulistas de jornais e das revistas nudistas. As fotografias compunham boa parte do que era impresso nas revistas e era sobre as imagens, e não sobre os textos, que os debates aconteciam. Todavia, embora as fotografias sejam o motivo dos debates aqui estudados, elas não sãoa base empírica do trabalho². Ao acicatarem o debate sobre a presença pública da nudez, assumiremos que "As imagens que mobilizam a consciência estão sempre ligadas à determinada situação histórica" (SONTAG, 2013, p.27). Ao centrarmos nossa atenção nos debates publicados, o foco das reflexões não são os "mecanismos da mobilização"(SONTAG, 2013), mas as representações erigidas nos embates entre defensores e detratores das publicações nudistas.

Inicialmente, situaremos o nudismo como uma das expressões do modo como o corpo passou a ser gerador de reflexões sobre a formação dos indivíduos e das sociedades no século XX. Depois, abordaremos a importância das fotografias na divulgação do nudismo. Finalmente, estudaremos como as revistas nudistas geraram representações conflitantes sobre o corpo e a nudez no Rio de Janeiro da década de 1950.

\section{PRIMEIRAS DÉCADAS DO SÉCULO XX: O CORPO EM EVIDÊNCIA}

No decorrer do século XX houve uma transformação na maneira como o corpo passou a ser visto e experimentado nas relações sociais. As "restrições puritanas" foram submetidas a uma "inversão, mais ou menos rápida, mais ou menos completa" (ORY, 2011.p.169) de valores que, até então, privilegiavam a rigidez e a lentidão. Essa mudança toca questões econômicas pelo fato de a atenção ao corpo se colocar em uma estrutura urbanizada e industrializada. Igualmente, ela se põe em um contexto cultural que pede um novo "critério epidérmico": as elites não mais vão "[...] se distinguir do rústico bronzeado, mas do operário ou do empregado pálido" (ORY, 2011, p.174). Nas primeiras décadas do século XX, "mundo se bronzeia e se desnuda". Nele o "movimento naturista vai agitar o século" (ORY, 2011, p.174), tornando-se fundamental no reconhecimento deque se "[...] assistiu certamente à maior reviravolta que 0 corpo humano jamais tenha conhecido em tão pouco tempo" (ORY, 2011, p.192).

No Brasil, o Rio de Janeiro foi o lugar onde o corpo e a movimentação corporal também se tornaram características da construção de novas sociabilidades. Constatouse uma "generalização de uma ética do ativismo" (p.567) ou uma "nova ética do corpo e da ação" (SEVCENKO, 2012, p.576). Muitos assumiram que "[...] tinham músculos e passaram a explorar as vantagens destes sobre os velhos e surrados miolos" (SEVCENKO, 2012, p.567). Entre outras coisas, essa exploração levou ao uso de roupas "leves, curtas, coladas ao corpo", exibindo "os músculos e formas torneadas do físico" (SEVCENKO, 2012, p.569). Formava-se um "complexo sistema articulado pelas noções básicas de limpeza, saúde e beleza". O corpo, "em geral semidespido, jovem, saudável, atlético e impoluto" (SEVCENKO, 2012, p.575),tornouse um marco da "capital irradiante". Surgia uma "[...] nova sensibilidade urbana acolhedora de uma diversidade e intensidade de práticas corporais", geradora, enfim, de "novas maneiras de viver" (SOARES, 2011, p. 2).

2 As fotografias utilizadas neste texto ilustrarão as representações que serão 0 alvo da discussão. Com esse procedimento mantemos à frente as advertências de Leite (1998), quando afirma que "na tradição europeia e acadêmica, o texto verbal foi consagrado", ao passo que as imagens ficaram relegadas "à condição de ilustração dispensável ou superlativa" (LEITE, 1998, p.39). Neste texto a ilustração por nós proposta fica entre os dois opostos apontados por Leite (1998). 
Toda essa atenção não deve levar à constatação de que se passou a contar com um "corpo potencialmente autônomo" (ORY, 2011, p.192). O medo da desmedida que poderia ser gerada pelo corpo levou a "[...] novas coerções justificadas pela saúde do organismo e pela exibição de um corpo sem dúvida saudável, [...] conforme aos cânones da beleza da época [...]" (ORY, 2011, p. 183). A visibilidade do corpo fomentou reservas quanto aos limites entre a manutenção e a criação de hábitos e costumes.

Sant'Anna (2014), contrapondo o eugenismo do "Sonho da beleza helênica", ajuda-nos a entender alguns elementos da resistência que a exposição da nudez teve no Brasil, mesmo em uma circunstância de grande exposição corpórea: "[...] para vários médicos, eugenistas ou não, num país com problemas gritantes de saneamento básico como o Brasil, a nudez era a expressão de aberrações físicas, doenças, deformidade e atraso" (SANT'ANNA, 2014, p. 62).

\section{A EVIDÊNCIA CORPORAL NO NUDISMO: A IMPORTÂNCIA DA FOTOGRAFIA}

Uma das justificativas dos nudistas para a sua prática era que ela, "[...] ao satisfazer a 'curiosidade natural' de ver o corpo nu, diminui a promiscuidade, o sexo pré-nupcial, a perversão sexual e a prostituição" (HOFFMAN, 2015, posição 223³) (tradução nossa). Ver corpos nus era algo que não se reduzia às praias e às colônias nudistas: essa exibição tornouse um imperativo nas publicações produzidas no bojo do movimento. Vejamos os modos e as consequências desse imperativo.

As fotografias nas publicações nudistas tinham grande valor na sua divulgação. Harp (2014) mostra que nelas buscava-se "regulamentar a nudez coletiva" (posição 1190) (tradução nossa). A tentativa de tirar dessas fotografias a possibilidade de gerar um olhar "ostensivamente erótico" (HARP, 2014) (tradução nossa), dava-se "Com ilustrações de pessoas nuas, [...] fazendo exercícios em ambientes naturais" (HARP, 2014, posição 1190) (tradução nossa). A necessidade de divulgar o nudismo por meio de revistas assumiu que essas publicações eram "Verdadeiras ferramentas de propaganda, [...] Com o objetivo de dar uma imagem positiva e quotidiana do naturismo" (BARTHE-DELOIZY, 2003, p.145) (tradução nossa). Atrelava-se 0 movimento às atividades recreativas e familiares, com fotografias apresentando uma "estética dessexualizada" (HOFFMAN, 2015, posição 2274) (tradução nossa). Conectava-se o nudismo à vida cotidiana de seus praticantes. Porém, faziam isso evidenciando um padrão corporal magro, branco e que buscava lembrar a estatuária grega (BARTHE-DELOIZY, 2003, p.145).

Estava em curso um processo de transformação das relações que as pessoas entretinham com seus corpos. A sexualidade e o lugar público que ela poderia ocupar ganhavam importância. Nas primeiras décadas do século XX, Hoffman (2015, posição 602) explica que a sociedade norte-americana passou a aceitar uma maior exibição do corpo, em detrimento de roupas que dificultavam a movimentação corporal, estimulando um olhar mais simpático, ou menos condenatório, aos nudistas. Isso não significou celeridade no que diz respeito às mudanças legais, gestando um ambiente conflitivo. Houve um choque com a moral materializada nas leis em voga. Deu-se a perseguição aos campos e lugares em que o nudismo era praticado, ao lado da apreensão de revistas e filmes que tematizavam o movimento.

3 Alguns livros utilizados foram consultados na versão Kindle. Nessa versão a localização das citações se dá pela "posição" em que se localiza o texto citado. 
As revistas ligadas ao nudismo lidaram com a dificuldade de se distanciarem da pornografia 4 . A afirmação ou a negação dessa ligação foi palco de luta com desfechos diferentes, de acordo com o país em que ela ocorreu. Na França havia um grande público consumidor dessas publicações que as viam como veículos de pornografia (HARP, 2014, posição 1194). Também nos Estados Unidos, mesmo que as publicações nudistas se assumissem como recreativas e terapêuticas, elas serviram como "fontes de pornografia" (HOFFMAN, 2015, posição 328) (tradução nossa).Estava em jogo a possibilidade desse consumo ser desafiado pela divulgação dos “benefícios de se desnudar"(HARP, 2014, posição 1775) (tradução nossa) em termos físicos, mentais e morais.

Isso fez com que a escolha das fotografias ocorresse cuidadosamente. Mas, "Como diferenciar uma fotografia de um nu naturista, de uma fotografia de um nu artístico, acadêmico, erótico, pornográfico?" (DESCAMPS, 1972, p.159)(tradução nossa). Os editores lançaram mão de procedimentos para que as fotos realizassem determinadas "mobilizações da consciência" (SONTAG, 2013), tais como a utilização de fotos que exibiam grupos de pessoas participando de jogos e brincadeiras (HOFFMAN, 2015, posição 2269), bem como o retoque gráfico nas fotos, alterando pelos pubianos e os próprios órgãos sexuais (posição 2267). Solicitava-se aos leitores a submissão de fotos de famílias nudistas. Fotografias de duas mulheres juntas ou de grandes agrupamentos eram evitadas, pois, "[...] eles poderiam lembrar pin-ups, evocar homossexualidade, implicar sexo grupal” (HOFFMAN, 2015, posição 2273) (tradução nossa).

Figura 1 - Fotografias de grupos realizando práticas corporais eram uma das estratégias para construir um olhar não erótico à nudez humana.

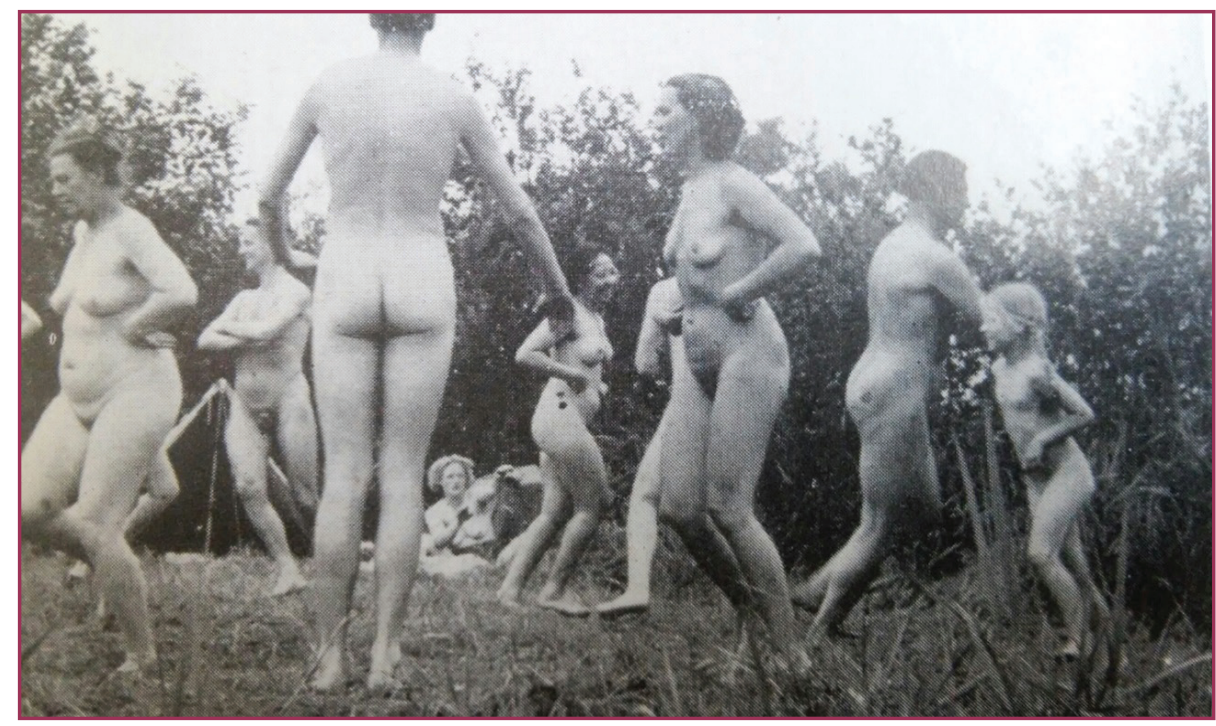

Fonte: SAÚDE E NUDISMO, 1953, n.13, p.34

Se de um lado as revistas divulgavam uma determinada imagem livre de conotação erótica, essa mesma conotação dava sustentabilidade econômica às revistas, aumentando suas vendas. Essa situação levou-as à publicação de fotos de corpos mais jovens e bonitos, intercalando-as com aquelas que não se encaixavam nesse cânone estético, tudo com muito critério, para"[...] ofuscar as linhas que separavam o pornográfico de representações visuais 
aceitáveis" (HOFFMAN, 2015, posição 2309) (tradução nossa).Como e quando alternar belos corpos com corpos fora dos padrões estéticos da época era decisão fundamental à sobrevivência dessas iniciativas editoriais.

\section{EMBATES SOBRE A NUDEZ NA “CAPITAL RADIANTE”}

Nas primeiras décadas do século XX, O'Donnell (2011) mostra que a cidade do Rio de Janeiro passou por mudanças que entrelaçaram rupturas econômicas, sociais e culturais à reconfiguração urbana gerada pela incorporação de porções litorâneas que levaram ao surgimento de um "Rio atlântico". Nele desenvolveu-se uma "nova territorialidade, e, com ela, novas formas de vivenciar, experimentar e representar os próprios princípios da urbanidade" (O'DONNELL, 2011, p.8). A "sociabilidade praiana" (p.10) fomentou um "estilo de vida fortemente calcado na exposição do corpo" (O’DONNELL, 2011, p.8). Em 1930 Afrânio Peixoto afirmou que "[...] bastava um passeio à praia encantada, à hora do 'cock-tail' para notar que a 'adhesão nacional a vida naturista é integral'” (BEIRA MAR, 19/01/1930, p.2). Embora essa afirmação pareça exagerada ${ }^{5}$, ela é um indício de que nessa sociabilidade que se construía o movimento nudista chamou diferentes tipos de atenção.

No final da década de 1920 começou a divulgação de notas e reportagens sobre 0 nudismo nos jornais cariocas. Em 1929, o Jornal do Brasil noticiava que em vários países 0 "número de adeptos cresce continuamente". A cada dois brasileiros "nascidos sob este sol escaldante, há, pelo menos, um nudista latente"(JORNAL DO BRASIL, 10 jan.1929, p.8). Sem contrapor o nudismo, advertiu-se os futuros adeptos: não "andarem nus pela Avenida Rio Branco. Evitar-se-ão, assim, congestionamentos" (JORNAL DO BRASIL, 10 jan.1929, p.8).

Nesse momento, o nudismo ainda era apresentado como uma proposta de reaproximação do homem à natureza (SOARES, 2016). O nudismo era uma "bela" utopia que não seria aceita em larga escala. Mas com a passagem dos anos, surgiram contrariedades em torno dessa adesão. Em 1939, Benjamin Costallat afirmou a existência de uma "perseguição ao nudismo". Essa perseguição só deveria ser exitosa se proibisse os "nudistas que não venham comprometer, inteiramente, o padrão humano firmado pela estatuária grega" (COSTALLAT, 28 out.1939, p.19). Desse momento até a movimentação editorial das revistas nudistas nos anos 1950, as menções jornalísticas mudaram, significativamente, de tom. Tornaram-se constantes as narrativas de apreensões e advertências sobre as "obscenidades" das revistas do movimento. Corrente, também, tornou-se a necessidade das revistas nudistas explicarem seus motivos, procedimentos e, principalmente, a veiculação das fotografias. Palavras e imagens cimentaram a existência a uma "pedagogia do corpo" no contexto carioca durante a década de 1950.

\subsection{As apreensões e as advertências: a nudez pornográfica}

Ao relatar uma apreensão de exemplares da revista Saúde e Nudismo, o Diário da Noite afirmou a continuidade de uma "campanha contra publicações obscenas, que só servem para corromper a mocidade". Foi exaltada a atuação da Delegacia de Costumes contra uma revista "considerada altamente obscena" (APREENDIDA a revista..., 21 mar.1952, p.3). 0 posicionamento do jornal explicita-se ainda mais quando lemos que, consoante a tal revista,

5 Em muitas reportagens da época, a palavra nudismo não se associava apenas aos praticantes de um movimento, mas englobava qualquer demonstração do corpo avaliada como exagerada, considerando os padrões da época. Afrânio Peixoto, no artigo citado acima, menciona nudismo e naturismo como conceitos ora intercambiáveis, ora como manifestações diferentes. Isso, talvez, explique o fato de ele ter avaliado a maior visibilidade corporal nas praias cariocas com uma "adesão integral" ao nudismo. Nas fotos utilizadas na reportagem do jornal Beira Mar, os "naturistas" estão com trajes de banho. 
"Trata-se de uma publicação com ilustração fria de mulheres e homens inteiramente desnudos, em quase todas as páginas sendo flagrante o propósito da revista provocar a concupiscência humana com fins [...] exclusivamente mercenários" (RONDA policial, 3 abr.1952, p.5).

Rolim (2000) observa que as Delegacias de Costumes e Jogos deveriam verificar a "[...] conveniência ou necessidade de impedir a circulação de publicações obscenas, tanto as ilustradas como as simplesmente escritas" (ROLIM, 2000, p.156). Elas eram as responsáveis pelas abordagens policiais às publicações nudistas, e, dessa forma, suas ações e seus delegados eram constantes alvos de elogios nos relatos publicados nos jornais.

O Código Penal Brasileiro de 1940 (BRASIL, 1940), no seu capítulo VI, tratou do Ultraje Público ao Pudor. Esse trato se deu em dois artigos: 0233 e 0 234, versando sobre 0 ato obsceno e o escrito ou objeto obsceno, respectivamente. A letra da lei apoiava a ideia de que as apreensões das revistas justificavam-se, pois as fotografias infringiam a proibição da "[...] distribuição ou exposição pública, de escrito, desenho, pintura, estampa, ou qualquer outro objeto obsceno". Os acusados seriam presos por um período de seis meses a dois anos, ou, alternativamente, pagariam multa de "dois mil cruzeiros a cinco mil cruzeiros" (IMORAIS, 9 dez.1952, p.6). Vale a pena detalhar que 0 inciso 1 do artigo 234 afirmava que "Incorre na mesma pena quem: I) vende, distribui ou expõe à venda ou público qualquer dos objetos referidos neste artigo" (BRASIL, 1940, s.p.).

O caráter ofensivo que se enxergava nas fotografias de nus dava-se devido ao apelo comercial produzido por elas. Para esses críticos, a intenção dos editores era explorar, economicamente, a nudez de homens e, sobretudo, de mulheres. No dia 15 de julho de 1952 foi comemorada outra apreensão de várias revistas em bancas espalhadas pela cidade do Rio de Janeiro ("SAÚDE E NUDISMO" e outras..., 15 jul.1952, p.5). O mesmo ocorrera em outras cidades, palcos de ações policiais contra revistas "consideradas imorais" (PROIBIDA em Belo Horizonte..., 12 set.1955, p.11).

Em agosto de 1958, mais uma blitz ocorreu no Rio de Janeiro "Para evitar que certas publicações possam servir de estímulo à prática de desatinos pela chamada 'juventude transviada"'. Com efeito, essas publicações "estampam fotografias e textos atentatórios a moral publica" (JUIZADO de menores..., 2 ago.1958, p.2). Clamava-se a "urgência de uma repressão a pornografia". Em folhetos, cartazes e vários anúncios de muitos produtos, "tudo se utiliza diabolicamente da maldade humana" ("DIZE-ME o que lês..., 1‥ jul.1958, p.9).Nessas matérias, a característica obscena da revista não existiria se nas fotos houvesse "vislumbre de naturalidade artística e científica". Todavia, as imagens de "homens e mulheres nus feriam 0 decôro público" (PUBLICAVAM fotografias obcenas, 16 jun.1952, p.2).

\subsection{As fotografias como divulgação da legalidade e da naturalidade da nudez}

Em 1953 foi trazida à baila no Brasil a discussão sobre a legalidade das revistas que ocorreu nos Estados Unidos. Em um editorial criticou-se a justiça brasileira citando sentenças de juízes americanos, para quem os nudistas "não incitam pensamentos de concupiscência no espírito do homem normal" (NÃO incitam maus pensamentos, 1953, p.4). Em outra menção judicial publicada, a sexualidade foi tida como meramente fisiológica para que, desse modo, fosse encarada com a "calma imparcialidade do cientista". Lemos que essa era uma estratégia para que o sexo se tornasse uma "verdade". Verdade "bastante sadia para ser ensinada" (A PALAVRA da justiça, 1954, p.10). 
Comemoravam-se decisões judiciais favoráveis aos editores, levando-os a afirmarem que as absolvições que conseguiam eram "honroso epílogo". Em uma dessas comemorações, o editor concordava em "regular publicações desse gênero", afirmando que havia outras publicações com "impressionantes fotos em suas páginas, de insinuantes 'sex-appeal'", que "sugerem maldade" (MORAL de ontem e de hoje, 1953, p.2). Contra elas, o editor nudista era favorável à "[...] constituição de uma comissão composta de pessoas qualificadas para assentarem medidas que habilitem o Estado agir contra as chamadas publicações imorais" (CADA um no seu ofício, 1953, p.16), não hesitando, assim, em aplicar a outras publicações o crivo que the era imputado.

Em outra sentença judicial publicada explicitou-se não apenas o cerne da questão, a saber, definir a "obscenidade" das revistas nudistas. Ao ponderar que a revista não era "obscena" nos termos do artigo 234 do Código Penal de 1940, o juiz percebe algumas das posturas editoriais analisadas por Hoffman (2015) que buscavam delimitar a nudez das revistas nudistas de uma nudez que era qualificada de pornográfica:

No exame a que submetemos a citada publicação - convém salientar - também encontramos, em conjunto com pessoas adultas, crianças e alguns adolescentes, talvez acompanhados de parentes próximos, ou de seus pais, o que desde logo exclue a obscenidade que se quer emprestar a mesma publicação. 0 caso em espécie cifra-se em saber-se se 0 'nu' nas condições publicadas caracteriza-se 0 crime previsto (UM voto de louvor, 1953, p.2).

Para fazer frente às acusações de imoralidade, mapeava-se a origem das críticas dirigidas às revistas. Boa parte dos argumentos contrários advinha de três fontes: "os puritanos (ideias de 1900 aplicadas em 1953), os falsos puritanos (homens cuja integridade moral é só para inglês ver); e os que desconhecem o nosso ideal" (CONSIDERAÇÕES em torno do nudismo, 1953, p.38). De um modo complementar, diagnosticava-se a forma como as publicações eram "vistas". Falava-se em "uma infinidade de tipos de leitores": aqueles que apenas "[...] folheiam, à primeira vista detendo-se mais nas fotos e, ao folhear novamente lêem um outro artigo, fixando-se novamente nas figuras". Além disso, existiam os "mais apurados, [que] lêem e vêem a revista folha por folha, artigo por artigo, para depois fazerem um exame nas fotos" (HÁ GOSTO para tudo, 1952, p.4).

A postura mais frequente para tornar viável e aumentar a circulação das fotografias era aliá-las às vantagens terapêuticas e morais do nudismo. Divulgá-lo era um "dever social de externar o nosso pensamento". Propugnava-se que "[...] a prática do nudismo em conjunto aprimora os espíritos e o ambiente". Os nudistas não deveriam "guardar dentro de nós, a nossa sabedoria, o nosso conhecimento" (É NECESSÁRIO o campo de nudismo?, 1953, p.14). As revistas almejavam a seguinte possibilidade: "Quando o homem descobre a si mesmo, daí começa sua vida. O espírito guia-se pela ética e o amor à arte, educando o corpo na evolução. $\mathrm{O}$ 'perfeito' identifica-se com ambos que procuram a comunhão da natureza" (O HOMEM e a natureza,1953, p.22).

As publicações viam-se como possibilidades concretas de fomentar uma "nova mentalidade que renova os meios sociais". Desejavam preparar homens e mulheres para "uma nova mentalidade entre classes sociais, para elevar o nível do homem em si". Para tanto, o nudismo era tomado como a realização de uma "harmonia com a própria natureza". Nessa definição da tal natureza humana, o nudismo seria uma prática em que a distinção corpoespírito poderia ser "harmonicamente" superada por essa "nova mentalidade" (O HOMEM e natureza, 1953, p.22). 
Figura 2 - O corpo da fotografada está em primeiro plano e ela olha, diretamente, para a objetiva, o que era visto como "incitação sexual". É fácil perceber que o céu que se vê ao fundo é uma montagem.

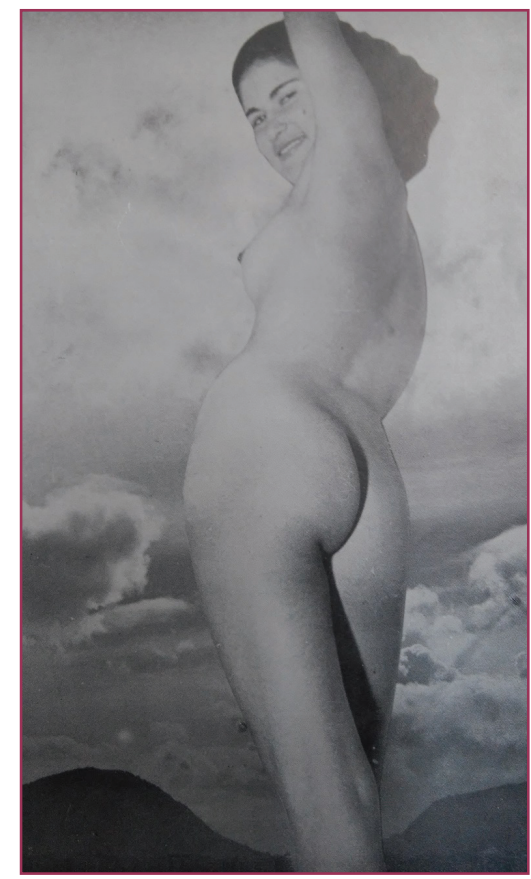

Fonte: SAÚDE E NUDISMO, 1953, n.18, p.15

Essa "nova mentalidade" estava distante, levando os editores a um pragmatismo na elaboração de suas revistas. No esforço de fazer com que a circulação acontecesse, elas passaram a ser vendidas dentro de envelopes que impediam a visualização da capa. Embora fosse assumido que esse procedimento fosse "coisa que comercialmente nos prejudica", menos prejudicial seria contornar os problemas colocados por "falsos puritanos que por aí perambulam pregando aquilo que não praticam e praticando o que proíbem em seus conselhos de pureza" (ACUSAMOS os que combatem o nudismo, 1953, p.1).

Figura 3 - As fotografias que exibem homens nus primam pelos padrões estéticos analisados por Hofmann (2015) e Harp (2014).

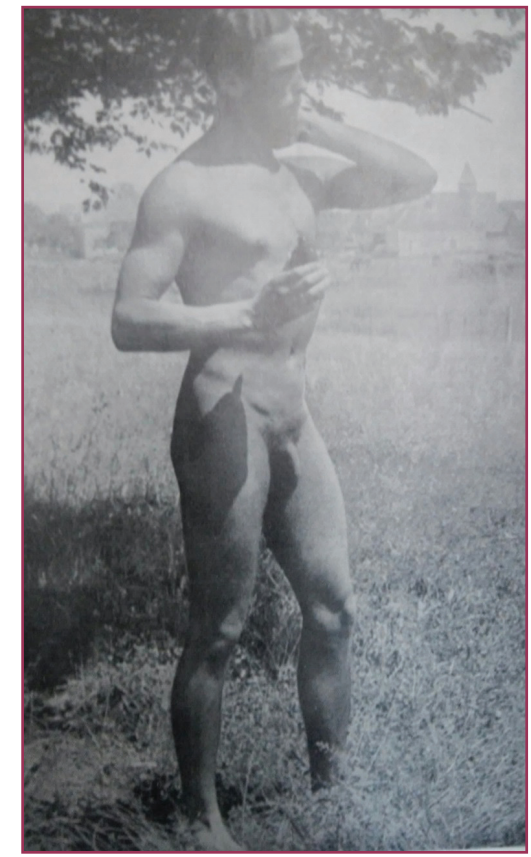


A disputa jurídica em torno da "obscenidade" das revistas também era tomada como elemento positivo para a expansão do movimento. Tanto uma "serena objetividade" quanto a narração com "um tom deveras picante, para contentar a ânsia de escândalos, dos quais 0 grande público está sempre sequioso", poderiam levara um maior "conhecimento dêste sistema de vida". Assim, as pessoas iam se "[...] habituando gradativamente à idéia de que homens e mulheres podem viver juntos completamente despidos, sem que aconteça nada de anormal" (RESENHA de gimnosofia, 1953, p.22).

Figura 4 - As capas das revistas, geralmente, eram coloridas. Na fotografia abaixo, vemos a tentativa integrar a nudez às atividades da vida cotidiana.

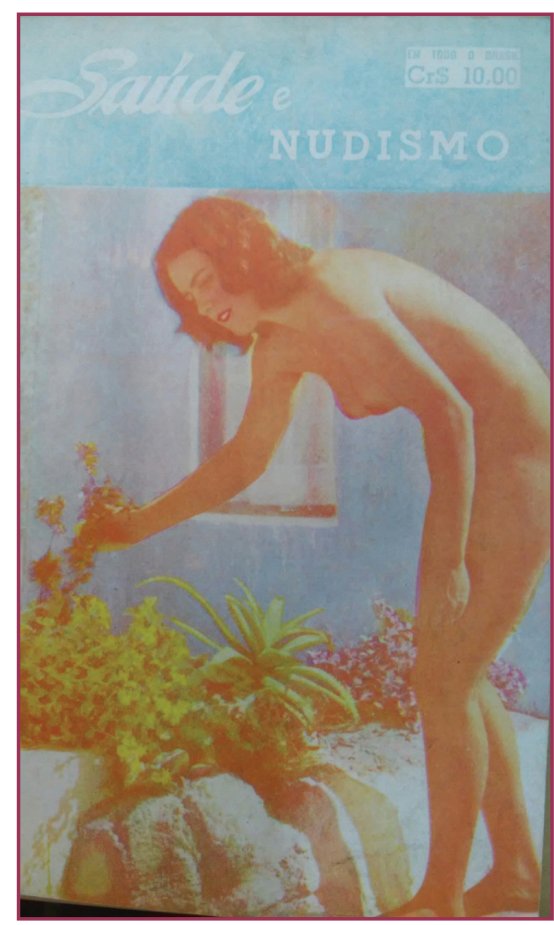

Fonte: SAÚDE E NUDISMO, 1952, n.4a.

Viabilizar a publicação de fotos que não fossem "arranjadas", zelando pelo "serviço fotográfico estampado em nossas páginas", levava os editores a estabelecerem "contratos com alguns campos de nudismo europeus", suprindo suas revistas com "um grande sortimento de fotos autênticas das atividades do livre culturismo no Velho Mundo" (HÁ gosto para tudo, 1952, p.4). Publicar as fotografias que chegavam demandava cuidados e procedimentos mais eficientes para sua apresentação. Era argumentado que fotografias que exibiam nus artísticos, contrariamente ao raciocínio mais comum, tinham sua eficiência do "ponto de vista de propaganda". O procedimento usual era apresentar uma história envolvendo as benesses nudistas, tendo na mesma página uma "fotografia de mulher nua, com um corpo sempre belo, escultural, que chama a atenção" (NUS artísticos como propaganda, s.d., p.15). Esse procedimento, repetido em sucessivos números, levaria a um "tratamento homeopático: lento, demorado, porém seguro", por meio do qual o leitor, tornar-se-ia "também adepto e amigo da cultura do corpo livre". Por essas razões, era inegável a ideia de "que amplas ilustrações constituem o meio mais prático e seguro para propagar e espalhar pelo mundo as ideais do nudismo" (NUS artísticos como propaganda, s.d., p.15). 
Figura 5 - Na legenda da foto lemos "Num bucólico recanto de Berlim, uma nudista prepara-se para o Banho".

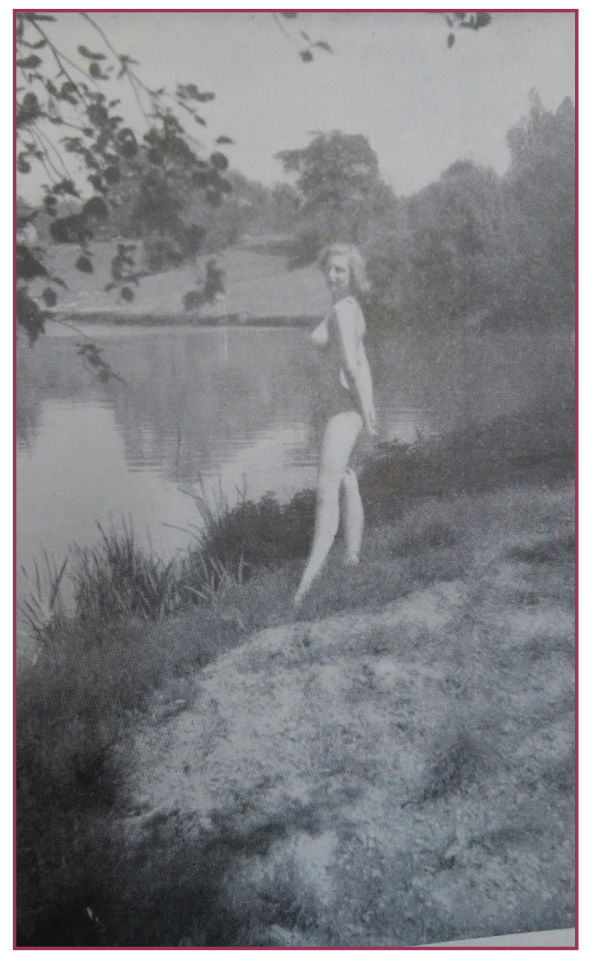

Fonte: SAÚDE E NUDISMO, 1952, n.4, p.9.

Ao utilizarem as fotografias como o principal meio de divulgação do movimento, compreende-se 0 interesse gerado pelas imagens. Acalentava-se essa curiosidade por parte dos leitores, afinal "Que mal há nisso?...É por demais sabido que a curiosidade é tão natural quanto a fome" (NUDISMO e beleza, [195?], p.1). Desfazia-se, desse modo, o clima de transgressão percebido como existente em leitores ao tomarem suas decisões nas bancas. Mesmo os editores, ao lidarem com a nudez das fotos, confessavam o "receio de cair no ridículo ou macular os espíritos menos esclarecidos" (NUDISMO e beleza, [195?], p.1), fossem eles os censores, fossem eles os consumidores, imediatamente, não interessados na cara reaproximação à natureza!

Para a tarefa de agradar sensibilidades e interesses tão díspares, o estímulo era assumir qualquer "sacrifício [...] falar aos homens, aos povos e a todos aqueles que se interessam pelo Esporte, a Beleza, a Arte e pelo Nudismo (NUDISMO e beleza, [195?], p.1).Dedicavam-se ao "cultivo do Belo, da Arte, da Natureza e do Esporte"; colocavam-se como objetivos "difundir esses desejos dentro de sua feitura", por meio de "ensinamentos, conselhos, regras de higiene e saúde". Tudo isso "com farta ilustração", de modo a fazer com que "cada número lançado represente mais um esforço e uma fidelidade e estímulo às suas preocupações" (NUDISMO e beleza, [195?], p.2).

O estabelecimento da fronteira que permitisse afirmar serem as revistas nudistas publicações de "interesse popular" e não "obscenidades" era visto como necessário e resultante de um "longo e minucioso período mental" que possibilitasse à "mente dos leitores" compreender que "tais fotografias, inseridas em revistas de primeira qualidade", eram apenas "propaganda [...] do mais sadio meio de vida". Se as fotografias eram "fator primordial de propagação do nudismo", buscava-se separar as revistas nudistas das "publicações de péssima qualidade", que sob a justificava de serem "humorísticas", utilizavam "fotografias pornográficas" (VIVER bem, mas como?, [s.d.], p.32). 
Ao tacharem algumas fotografias como pornográficas, diferenciando-as daquelas que publicavam em suas revistas, os editores explicavam quea "pornografia" que os leitores viam existir nas revistas nudistas provinha, de fato, de um determinado olhar. Esses olhos estariam deturpados pelos valores corrompidos da sociedade em que viviam: "Há pessoas que julgam pornográficas tais fotografias; não estaria a pornografia nas tais pessôas?" (VIVER bem, mas como?[s.d.], p.32).

\section{CONCLUSÕES}

Como ponderar aquilo que diferentes épocas consideram como pornografia e/ou obscenidades? Como avaliar esse olhar? As revistas nudistas seriam "atos obscenos", tal qual se definiam esses atos no Código Penal de 1940? Ou as fotografias seriam inevitáveis à expansão do movimento nudista e sua pretendida reaproximação à natureza via exposição corporal? Em torno dessa celeuma construíram-se as reflexões deste artigo. O cruzamento de representações conflitantes sobre o corpo e a nudez circulantes em jornais, pareceres judiciais, documentos legais e pelos textos dos divulgadores do nudismo radicados no Rio de Janeiro evidenciam a dificuldade de atribuirmos um único sentido às diferentes representações sobre o corpo durante a década de 1950.

Deixando a situação ainda mais exigente de cuidados analíticos, a contrariedade à veiculação de fotografias de corpos nus flertava com a possibilidade de aceitá-las, desde que fossem ressaltados traços "científicos" ou "artísticos" do corpo. Do lado dos editores, vimos o pragmatismo que os levava à observância do aumento das vendas. A divulgação da autoproclamada nobreza dos ideais nudistas reconhecia, acalentava e se sustentava na "curiosidade" que tinham os "leitores".

Nudez científica, artística, obscena, comercial, pornográfica. A discussão permitiu vislumbrar a construção de uma grande dificuldade de se tirar o corpo de foco. Esse foco sugere uma "pedagogia do corpo" (SOARES, 2016)que se instalava no cotidiano carioca. A discrepância dos olhares dados à nudez sinaliza a emergência de uma nova sensibilidade ao corpo no período em tela. Para melhor entendê-la, vimos que a história do nudismo oferece panoramas a serem contemplados com grande interesse.

\section{REFERÊNCIAS}

ACUSAMOS os que combatem o nudismo. Saúde e Nudismo: alma sã num corpo são. Rio de Janeiro, 1953, n.10, p.1.

APREENDIDA a revista "saúde e nudismo" e processados um comissário de polícia e um médico, seus diretores.Diário da Noite, Rio de Janeiro, 21 mar. 1952.

BARTHE-DELOIZY, Francine. Géographie de lanudité. Paris: Éditions Bréal, 2003.

BAUBÉROT, Arnaud. Histoire du naturisme: le mythe du retour à la nature. Rennes: Universitaires de Rennes, 2004.

BOLOGNE, Jean-Claude. História do pudor. Rio de Janeiro, Lisboa: Elfos, Teorema, 1990. 
BRASIL. Presidência da República. Casa Civil. Decreto-lei n. 2.848, de 7 de dezembro de 1940: Código Penal. Diário Oficial da União, Seção 1, p. 23911, 1940. Disponível em: <http://www. planalto.gov.br/ccivil 03/decreto-lei/Del2848.htm>.Acesso em: 24 abr. 2016.

CADA um no seu ofício. Saúde e Nudismo: alma sã num corpo são. Rio de Janeiro, n. 12, 1953, p.16.

CARR-GOMM, Philip. A brief history of nakedness. London: Reaktion Books, 2010. [versão Kindle]

CHARTIER, Roger. A História Cultural: entre práticas e representações. Rio de Janeiro: Bertrand Brasil, 2002.

CONSIDERAÇÕES em torno do nudismo. Saúde e Nudismo: menta sã num corpo são. Rio de Janeiro, p. 38,1953.

COSTALLAT, Benjamin.O direito ao nudismo. Beira Mar, Rio de Janeiro,p.19, 28 out.1939.

DEL PRIORE, Mary. Histórias íntimas: sexualidade e erotismo na história do Brasil. São Paulo: Planeta do Brasil, 2011.

DESCAMPS, Marc-Alain.Le nu et le vêtement. Paris: Éditions Universitaires, 1972.

"DIZE-ME o que lês e eu te direi quem és". Diário da Noite, Rio de Janeiro, p.9, 1‥ jul,1958.

É NECESSÁRIO o campo de nudismo? Saúde e Nudismo: alma sã num corpo são. Rio de Janeiro, 1953, n.17, p.14.

É NECESSÁRIO o campo de nudismo? Saúde e Nudismo: alma sã num corpo são. Rio de Janeiro, n. 17, 1953, p.16.

HÁ GOSTO para tudo. Saúde e Nudismo: alma sã num corpo são. Rio de Janeiro, n. 6, 1952, p.4.

HARP, Stephen L. Au Naturel: naturism, nudism, and tourism in twentieth-century France.

Louisiana: Louisiana State University, 2014. [versão Kindle].

HERMAN, Arthur. A ideia de decadência na história ocidental. Rio de Janeiro: Record, 1999.

HOFFMAN, Brian. Naked: a cultural history of American Nudism. New York: New York University, 2015. [Versão Kindle].

O HOMEM E A NATUREZA. Saúde e Nudismo: alma são num corpo são. Rio de Janeiro, 1953, n 17, p. 22.

IMORAIS. Diário da Noite, Rio de Janeiro, p.69, dez.1952.

JORNAL DO BRASIL, Rio de Janeiro, 10 jan.1929.

JUIZADO de menores: revistas censuradas. Diário da Noite, Rio de Janeiro, 2 ago.1958.

LEITE, MíriamLifchtiz Moreira. Texto visual e texto verbal. In: LEITE, MíriamLifchtiz Moreira; FELDMAN-BIANCO, Bela (Orgs.). Desafios da imagem: fotografia, iconografia e vídeo nas ciências sociais. Campinas,SP: Papirus, 1998. p.37-50.

LINHALES, MeilyAssbú.Esporte e escola: astúcias na 'energização do caráter' dos brasileiros. In: DEL PRIORE, Mary; MELO, Victor Andrade. (Org.). História do esporte no Brasil: do império aos dias atuais. São Paulo: Editora da UNESP, 2009. p. 331-358. 
MORAL de ontem e de hoje. Saúde e nudismo: alma sã num corpo são. Rio de Janeiro, 1953, n.18, p.2.

NÃO incitam maus pensamentos. Naturismo: Revista de Gimnosofia, n.11, 1953, p.4.

NATURISMEet éducationcorporelle: dês projetsréformistesauxprises em compte politiques et éducatives (XIXe - milieuduXXesiècles). Paris: L'Harmattan, 2005.

NATURISMO. In: MARZANO, Michela (Org.). Dicionário do corpo. São Paulo: Loyola, Centro Universitário São Camilo, 2012. p.707-710.

NUDISMO e beleza. São Paulo, v.1, n. 3, [195?].

NUS artísticos como propaganda. Vida e Beleza: gimnica e naturismo. São Paulo [s.d.], n.4, p.15.

O'DONNELL, Julia Galli. Um Rio Atlântico: culturas urbanas e estilos de vida na invenção de Copacabana. 2011. 298 f. Tese (Doutorado) - Programa de Pós-graduação em Antropologia Social, Museu Nacional, Rio de Janeiro, 2011.

ORY, Pascal. O corpo ordinário. In:CORBIN, Alain; COURTINE, Jean-Jacques; VIGARELLO, Georges (Orgs.). História do corpo: as mutações do olhar - o século XX. 4.ed. Petrópolis, RJ: Vozes, 2011. v.3, p. 155-196.

A PALAVRA da justiça. Naturismo: Revista de Gimnosofia, n. 15, 1954, p.10.

PROIBIDA em belo horizonte a venda de revistas imorais. Diário da Noite, Rio de Janeiro, p.11,12 set. 1955 .

PUBLICAVAM fotografias obcenas. Diário da Noite, Rio de Janeiro, p.2,16 jun.1952.

RESENHA de gimnosofia. Naturismo: revista de gimnosofia. Rio de Janeiro, 1953, n.7, p.22.

ROLIM, Rivail Carvalho.A reorganização da polícia no Estado do Paraná nos anos 1950.

Revista de História Regional, v. 5, n.1, p. 153-166, 2000. Disponível em: <https://www.faecpr. edu.br/site/documentos/revista historia regional70.pdf>.Acesso em: 24 abr.2016.

RONDA policial.Diário da Noite. Rio de Janeiro, p.53, abr.1952.

SANT’ANNA, Denize Bernuzzi. História da beleza no Brasil. São Paulo: Contexto, 2014.

SAÚDE e nudismo: alma sã num corpo são. Rio de Janeiro, 1952, n. 4

"SAÚDE e nudismo" e outras publicações obcenas. Diário da Noite, Rio de Janeiro, p.5, 15 jul.1952.

SAÚDE e nudismo: alma sã num corpo são. Rio de Janeiro, 1953, n.17, p.9.

SAÚDE e nudismo: alma sã numcorpo são. Rio de Janeiro, 1953, n.13, p.34.

SAÚDE e nudismo: alma sã num corpo são. Rio de Janeiro, 1953, n.18, p.15.

SAÚDE e nudismo: alma sã num corpo são. Rio de Janeiro, p.2, [s.d].

SEVCENKO, Nicolau. A capital irradiante: técnica, ritmos e ritos do Rio. In: SEVCENKO, Nicolau (Org.). História da vida privada no Brasil - República: da Belle Époque à Era do Rádio. 2. ed. 
SOARES, Carmen Lúcia. As roupas nas práticas corporais e esportivas: a educação do corpo entre o conforto, a elegância e a eficiência (1920-1940). Campinas-SP: Autores Associados, 2011.

SOARES, Carmen Lúcia. Três notas sobre natureza, educação do corpo e ordem urbana (19001940). In: SOARES, Carmen Lúcia (Org.). Uma educação pela natureza: a vida ao ar livre, o corpo e a ordem urbana. Campinas-SP: Autores Associados, 2016. p.9-46.

SONTAG, Susan. Sobre fotografia. 7.reimp.São Paulo; Companhia das Letras, 2013.

UM VOTO de louvor. Saúde e Nudismo: alma sã num corpo são. Rio de Janeiro, 1953, n.17, p.2.

VIDA E BELEZA: gimníca e naturismo. São Paulo, n.4, [s.d.].

VILLARET, Sylvain. Naturismo e educação corporal (fim do século XIX e início do século XX): uma "natureza" em movimento. In: SOARES, Carmen Lúcia (Org.). Uma educação pela natureza: a vida ao ar livre, o corpo e a ordem urbana. Campinas, SP: Autores Associados, 2016. p. 69-90.

VIVER bem, mas como? Vida e Beleza, São Paulo, n.4, [s.d.], p.32. 


\section{Apoio financeiro:}

CNPq e Fundação Araucária 